\title{
Bibliometric Analysis of the Global Research on Precision Medicine
}

\section{Baoyue Zhang}

Beijing University of Chinese Medicine

\section{Sajid Ali}

The University of Lahore

\section{Tianhui Xuan}

Beijing University of Chinese Medicine

Yajie Zhao

Beijing University of Chinese Medicine

\section{Bo Ao}

China-Japan Friendship Hospital

\section{Xinyue Lu}

Beijing University of Chinese Medicine Junbai Chen

Beijing University of Chinese Medicine

\section{Pengfei Bao}

Beijing University of Chinese Medicine

\section{Shuang Yang}

Beijing University of Chinese Medicine

\section{Qian Huang}

Beijing Tiantan Hospital

\section{Ruifeng Li}

Beijing University of Chinese Medicine

\section{Zhongwei Hou}

Beijing University of Chinese Medicine

\section{Youliang Huang ( $\nabla$ huangyl@bucm.edu.cn )}

Beijing University of Chinese Medicine https://orcid.org/0000-0001-8460-188X

\section{Research article}

Keywords: Precision medicine, Mapping knowledge domain, Bibliometric analysis

Posted Date: August 6th, 2020 
DOI: https://doi.org/10.21203/rs.3.rs-51342/v1

License: (c) (i) This work is licensed under a Creative Commons Attribution 4.0 International License. Read Full License 


\section{Abstract}

Background: Precision medicine provides medical solutions to stratified patients with personalised forecasting outcome as an important method of treatment in the medical field. This study aims at delivering a structured overview to carry out a bibliometric analysis of precision medicine retrospectively.

Methods: The compilation of data and the use of bibliometric methods based on academic databases (Science Citation Index-Expanded and PubMed) from January 1, 2010, to December 31, 2019. Research outputs, countries, institutions, authors, major journals, cited papers, hot subject areas were analysed.

Results: 8,566 papers related were identified (98.728\% in English) covering 1,975 different journals. The papers were originated from 109 countries; the USA held the predominant contributors with 4,635 papers, China was on second with 925 papers.

Conclusions: Precision medicine serves important purposes in clinical treatment, and widely used in the oncology, biochemistry, molecular biology field. The study summarised existing work and provided guidance for future research in this promising precision medicine area.

\section{Background}

Precision medicine is defined as targeted treatments towards to the needs of individual patients, which is based on genetic, biomarker, phenotypic and psychosocial characteristics [1]. The term "precision" was intended to embrace the whole spectrum, from prompting us to segment large populations into subgroups requiring different therapy, which is always personalised and is expected to herald a rapid development of new pharmacotherapies [2]. The prospect of applying the concept of precision medicine has been dramatically improved by the recent development of large-scale biologic databases like the human genome sequence, computational tools for analysing large sets of data, and powerful methods for characterising patients, such as proteomics, metabolomics, genomics, diverse cellular assays, mobile health technology [3]. For this reason, the rare diseases and uncommon cancers could be guided realtime, individualised prevention and therapeutics for improved results at all by using the increased knowledge stemmed from precision medicine about the biological pathways noting [4]. There are already "targeted" treatments such as imatinib mesylate which is highly effective against a form of blood cancer known as chronic myeloid leukaemia for the past few years [5]. And the same approach could be applied in other discussions of medicine [6]. The most obvious of those spheres are inherited genetic disorders and infectious diseases, but promise for many other diseases and environmental responses. Jones, P. A. found a growing emphasis on recent drug discovery efforts has been on targeting the epigenome (DNA methylation and histone modifications) [7]. Xiong, H. Y. developed a machine-learning technique to facilitate precision medicine and whole-genome annotation [4]. Robinson, D. established a multiinstitutional clinical sequencing infrastructure toward the development of a precision medicine framework for metastatic, which could impact treatment decisions for these affected individuals [8]. Further, obtainable data suggest the potential to better target public health efforts within populations by 
the development of precision medicine and utilises advances in new technologies and knowledge unlocked through big data [9]. It is noteworthy that precision medicine is of great significance to the biomedical industry as the next generation of diagnosis and treatment technology [10]. On the one hand, it can complement the discipline system of data science, and expand the medical application of big data. On the other hand, it can offer some better elicitation to the research to manage medically [11]. What we needed is a broad research program to encourage creative approaches to precision medicine, test them rigorously, and eventually use them to build the evidence base needed to guide clinical practice [12].

Bibliometric takes the literature as the unit of measurement, which on time as the axis, sets mathematics, statistics, and philology as a whole. Bibliometric is a quantitative measure more useful than "subjective" and intuitive assessment methods (such as peer review) which hailed as an "objective" measure of research quality, and has been used since scientific papers were first published in the seventeenth century [13]. Nowadays, as the main branch of information management, it is a common trend to use the bibliometrics field, utilises quantitative analysis and statistics to describe patterns of publications within a given theme, field, scientific development, funding purposes, individual evaluation international cooperation and citation patterns at the proper scales [14], which can yield insights on the global dynamics of science over time [15]. The bibliometric method has already been widely applied to medicalrelated topics such as cancer [14], mental health [16], Dendritic Epidermal T Cell (DETC) research [17], nonspecific low back pain research [18] and hepatology [19]. A few researchers have reported a great deal of productive work, which was instrumental in the development of specific targeting approaches on policy and clinical guidelines [20].

The study is covering keywords, most frequently cited papers, and analysis of bibliographic coupling, with local citation score, total local citation and h-index as an estimation index to gain an overview of precision medicine research during 2010 to 2019. The main purpose of it is developing a summative evaluation in conventional research aspects and innovative research aspects, it can be outlined as evaluating the author, national and institutional growth of research production, analysing patterns of research areas and suggesting global research trends in precision medicine to move forward into the future as a guide direction. The paper is composed of four themed chapters: methodology, results and discussion, conclusion, limitation. Part one deals with describing the study design, including data acquisition and processing search strategy, inclusion criteria, exclusion criteria and data analysis. Part two begins by laying out the evaluated result and has a discussion. The third part gives summative conclusions. Finally, we reflect on the remaining problem of this study.

\section{Materials And Methods}

This study is based on a bibliometric analysis design, a retrospective search was carried out using the Science Citation Index-Expanded (SCIE) and PubMed. The SCIE is considered as the largest comprehensive academic information resource in the world. It is regarded as the ideal databases for bibliometrics. It covers over 12,000 of the highest impact, quality scientific international journals and providing comprehensive data of papers, including more than 8,700 influential core academic journals in 
natural science, biomedicine and other research fields [21]. PubMed is also selected as the data resource, which is maintained by the United States National Library of Medicine and be considered as the worldleading language abstracting and indexing service [22]. Several studies have shown that SCIE and PubMed are of important potential impact to discipline development research. The edition of 2019 Journal Citation Reports (JCR), issued by the Institute for Scientific Information (ISI), has also been chosen as the source of our required data $[23,24]$.

The search strategy in SCIE is as follows: ("Precision Medicine" [topic] OR "Personalized Medicine" [All Fields] OR "Individualized Medicine" [All Fields] OR "Genomic Medicine" [All Fields] OR "Genetic Medicine" [All Fields]). The search strategy in PubMed was as follows: ("Precision Medicine" [MeSH Terms] OR "Personalized Medicine" [All Fields] OR "Individualized Medicine" [All Fields] OR "Genomic Medicine" [All Fields] OR “Genetic Medicine” [All Fields]).

According to the research retrieval objectives, a total of 8,651 papers were obtained, which covers all types of studies. Basis on the above, we developed criteria related to the research objectives based on topic, time span and other characteristics from the paper, to guide the search of the paper. The inclusion criteria were that the time span of publications is from 1st January 2010 to 31, December 2019, the search databases are limited to SCIE and PubMed; and the search field is precision medicine. The exclusion criteria were that we sifted out date paper, reprint, hardware review; and excluded projects of anonymous authors and repeated research paper.

Finally, 8,566 of them were included in the analysis according to the developed standards. Figure 1 shows these processes. 8,566 of them were included in the analysis according to the developed standards. Data for all studies were collected on 17 Jan 2020 solstice on 22 Jan 2020. We believe that this will have only a slight impact on the results by the change of time, as the data arise from global precision medical research over the relevant period and for comparative reasons. Finally, results were saved in TXT format and be sorted into tables according to different categories to promote the calculation of each index. The relevant retrieval of results was presented as a content schema with texts, figures and tables using Excel, Sci2-1.3.0, VOSview-1.6.5, HistCite-12.03.17.

\section{Results And Disscusion}

\section{A. Increase pattern of the annual publication amount.}

The timely change of the number of papers can highlight the development tendency of this field from a bibliometric perspective [25]. From the period of 2010 to 2019, the number of annual publications on precision medicine has been growing year by year as shown in Fig. 2. From the analysis, one may conclude that two papers were published in 2010, and 2,053 papers were published in 2019, which increases ranged 1,251.5 dozen times by comparison and shows the sharply increasing awareness in precision medicine. Furthermore, the result of the research can be roughly divided into three stages: 1) Initial stage (2010-2013). At this stage, the progress has slowed to a crawl. And the average annual increment is only 20.8. 2) A stage of development (2014-2016). During this period, the number of papers 
increased significantly, with an average annual growth of 82.568. 3) A stage of high-speed development (2017-2019). At this stage, the papers were in large quantities, with an average of 1,971 papers published each year. The number of publications dated between 2017 and 2019 (6,483 papers) accounts for $75.683 \%$ of all publications being analysed. This is more than three times as many figures as the previous period, which is in agreement with literature data. Among them, the number of published papers reached a peak in 2019 , with a total of 2,503 (35.483\% in all). From the above discussion, the conclusion can be reached that precision medicine has grown up to be a very important issue in medical research. Considerable more work, hopefully, will be done in this area, it is expected to reach new heights by 2022 .

\section{B. Geographical distribution of research output}

The number of national papers can objectively reflect the overall level and strength in the field of the researches of the country/territory [26]. Relevant papers are carried out on a global scale to figure out the actual conditions of research activities. The major spatial clusters in precision medicine global distribution were visualised in Fig. 3, which was in the USA, Western Europe, and Asia. Statistics demonstrate that 109 countries/territories published papers in this domain in total and countries/regions exceeding 100 papers account for $9.7 \%$ of these countries. Special concern has been given to the USA by the largest number of papers $(4,635,54.109 \%)$. As reported in previous studies, it is noteworthy that the USA has grabbed and controlled the top priority in the research field, with the advanced world medical levels, which is already had a discernible gap in the USA and the other countries. China ranked the second with 925 papers (10.799\%), staying one step ahead of other countries and having shown favourable development prospects. Followed by the UK $(925,10.799 \%)$, Italy $(711,8.300 \%)$ and Germany $(569$, $6.643 \%$ ). Nine advanced countries (USA, UK, Germany, Italy, Canada, France, Australia, Spain, Netherlands) are among the top ten countries/territories. Our data provide the direct evidence that the research of these developed countries generally takes the lead in the world and it is not startling to find this domination, which has appeared in many research fields, the phenomenon may be closely correlated with the top economic and science technology level of these countries. In general, recently precision medicine has attracted considerable attention in the scientific researches among nations, and it would be the common target of the world in the years ahead. This study provides a basis by pointing to global tendencies in the field of selection, and health information scientists should empirically investigate the national medical strategies of different countries [27].

C. Languages of publication and document types.

The 8,566 papers identified by the SCIE and PubMed between 2010 and 2019 include 8 document types. The document type mostly appeared was articles $(4,030,47.046 \%)$, followed by review $(2663,31.088 \%)$, editorial material $(1,052,12.281 \%)$, meeting abstract $(739,8.627 \%)$, book Chap. (111, 1.296\%), proceedings paper $(97,1.132 \%)$, letter $(82,0.957 \%)$, early access $(45,0.525 \%)$. As can be seen from Fig. 4 , article, review, and editorial material make up the main types of publications on precision medicine, which should be paid attention to when collecting and utilising applicable research information. 
The 8,566 papers included in the analysis were written in 10 languages. English forms the bulk of all languages $(8,457,98.728 \%)$, which satisfies the relevance of English in scientific research. Followed by German (45, 0.525\%), French (32, 0.347\%), Spanish (17, 0.198\%) and Chinese $(8,0.093 \%)$ were written. The sum of the other languages (Japanese, Czech, Esperanto, Hungarian, Italian) is only $0.083 \%$ of the total number of documents. None of the other languages excepting English is reaching in any case $1 \%$. This disparity is linked to the writing habits of researchers or the inclusion requirements of the SCIE and PubMed. Based on this, it is suggested that researchers in relevant fields should improve their capacity in English, which will promote international academic exchanges and cooperation.

D. Pattern of publication.

We confirmed 8,566 papers published in 1,974 journals. The result shows the ten most active journals, which published 794 papers comprising $9.269 \%$ of all 8,566 papers. In this tabular form (Table 1), Total Local Citation Score (TLCS) is the total citation frequency of the paper in the current data set [28]. The higher the TLCS of a paper is, the higher its influence is. The Impact Factor (IF) defined by Journal Citation Reports (JCR) is used to measure the relative importance of journals, especially contrasted to other journals in the same field. The findings in this study imply that over one-fifth of the papers analysed $(20.150 \%)$ were published in 35 journals. The Annals of Oncology was the journal with the most papers on precision medicine $(105,1.226 \%)$, with Total Local Citation Score of 1000, and IF of 14.19. The Total Publications, Total Local Citation Score, Impact Factor in 2018 of top 10 records journals are shown in Table $\Downarrow$, which provides a basis for researchers of precision medicine, and the top 10 journals showed a preference that most papers were published in professional journals. Such results can aid researchers by pointing to global trends in the field of selection. 
Table 1

Top 10 most productive journals of precision medicine during 2010-2019

\begin{tabular}{|lllll|}
\hline Rank & Journal & $\begin{array}{l}\text { Total } \\
\text { Publications }\end{array}$ & $\begin{array}{l}\text { Total Local Citation } \\
\text { Score }\end{array}$ & $\begin{array}{l}\text { Impact Factor in } \\
\text { 2019(IF) }\end{array}$ \\
\hline 1 & Annals of Oncology & 105 & 1000 & 18.274 \\
\hline 2 & Cancer Research & 93 & 338 & 9.727 \\
\hline 3 & Oncotargeto & 91 & 1100 & NULL \\
\hline 4 & Scientific Reports & 88 & 659 & 3.998 \\
\hline 5 & Journal of Clinical Oncology & 87 & 670 & 32.956 \\
\hline 6 & $\begin{array}{l}\text { Omics A Journal of } \\
\text { Integrative Biology }\end{array}$ & 78 & 476 & 2.507 \\
\hline 7 & PloS One & 67 & 522 & 2.74 \\
\hline 8 & Cancers & 63 & 346 & 6.126 \\
\hline 9 & Clinical Cancer Research & 61 & 1654 & 10.107 \\
\hline 10 & Personalized Medicine & 61 & 183 & 2.318 \\
\hline
\end{tabular}

E. Prolific institutions and their research impact.

From the distribution of research institutions and financial support institutions, a total of 6,860 institutions involved in the publication of "precision medicine" from 2010 to 2019. Harvard Med Sch is the most active institution in precision medicine research with the largest number of 229 papers (3.778\%). Table 2 and Table 3 show the total publications, country of top 10 fund support institutions and top 10 research institutions, respectively, which are ranked by the number of papers. The medical institutions listed in Table 3 are considered to be the market leader in the research of this field, and their research results and academic papers represent the highest standards in the world. Nine of ten research institutions come from the United States, the remaining one in Canada. To further characterise the effect of the category of institutions on research, we examined seven of them belong to the category of higher education institutions and found that precision medicine research is mostly performed by universities and research organizations. These findings also indicate that the top 10 funders are from the United States, China, the United Kingdom, the EUR and Canada. It was learned that institutions of higher learning give the established role of scientific research and blaze a new trail. At the same time, the effects of a close relationship between countries, institutions and funders also remained. Under the aegis of countries, relevant research institutions can be developed to provide a series of funds and promote the publication of research by individuals or groups. It is worth mentioning that research institutions from China mainland, Japan, Singapore, Taiwan and other East Asian countries/regions focus more on the research of precision medicine, by a high level of international cooperation. The rapid increase of related input and output may be closely related to the progress of scientific research and the growth of economic 
strength in Asia. The research has been considered by the advanced economies and also working with emerging and developing countries [21], which is drawing attention from the whole world.

Table 2

Top 10 Fund support institutions of precision medicie during 2010-2019

\begin{tabular}{|llll|}
\hline Rank & Research Institution & Total Publications & Country \\
\hline 1 & United States Department of Health Human Services & 1954 & USA \\
\hline 2 & National Institutes of Health & 1940 & USA \\
\hline 3 & National Natural Science Foundation of China & 506 & China \\
\hline 5 & NIH National Cancer Institute & 423 & USA \\
\hline 6 & NIH National Heart Lung Blood Institutel & 178 & USA \\
\hline 7 & Medical Research Council & 176 & EUR \\
\hline 9 & NIH National Human Genome Research Institutel & 139 & UK \\
\hline 10 & National Science Foundation & 139 & USA \\
\hline
\end{tabular}

Table 3

Top 10 Research institutions of precision medicie during 2010-2019

\begin{tabular}{|llll|}
\hline Rank & Research Institution & $\begin{array}{l}\text { Total } \\
\text { Publications }\end{array}$ & Country \\
\hline 1 & Harvard University & 617 & USA \\
\hline 2 & University of California System & 542 & USA \\
\hline 3 & National Institutes of Health NIH USA & 367 & USA \\
\hline 4 & Harvard Medical School & 326 & USA \\
\hline 5 & University of Texas System & 322 & USA \\
\hline 6 & Institut National De La Sante Et De La echerche Medicale & 272 & France \\
\hline 7 & Bnserm & 241 & USA \\
\hline 8 & University of London & 239 & USA \\
\hline 9 & University of Toronto & 228 & Canada \\
\hline 10 & Stanford University & 213 & USA \\
\hline
\end{tabular}

F. Productivity by authorship. 
First Authors, as recorded in the Affiliation field of SCIE and PubMed data, among the 8,566 papers, th,304 authors from 37 different countries. The top 10 authors published 328 papers, which are accounted for $3.829 \%$ of all. Table 4 explains the total publications, the rank of total publications, h-index, the rank of h-index, country, the institution of the top 10 authors in this field.

Table 4

Top 10 productive authors in publications of precision medicine during 2010-2019

\begin{tabular}{|c|c|c|c|c|c|c|}
\hline Author & $\begin{array}{l}\text { Total } \\
\text { Publications }\end{array}$ & $\begin{array}{l}\text { Total } \\
\text { Publications } \\
\text { Rank(\%) }\end{array}$ & $\begin{array}{l}\mathrm{H}- \\
\text { index }\end{array}$ & $\begin{array}{l}\text { Rank(h- } \\
\text { index) }\end{array}$ & Country & Institution \\
\hline Li,Jing & 38 & $1(44.40)$ & 36 & 6 & China & $\begin{array}{l}\text { Southern } \\
\text { Medical } \\
\text { University }\end{array}$ \\
\hline Zhang Ya & 36 & $2(42.00)$ & 14 & 7 & China & $\begin{array}{l}\text { Xian Jiaotong } \\
\text { University }\end{array}$ \\
\hline Lee,Jinhyuk & 35 & $3(40.90)$ & 4 & 9 & $\begin{array}{l}\text { South } \\
\text { Korea }\end{array}$ & $\begin{array}{l}\text { Korea } \\
\text { Research } \\
\text { Institute of } \\
\text { Bioscience \& } \\
\text { Biotechnology } \\
\text { (KRIBB) }\end{array}$ \\
\hline Wang Jing & 35 & $4(40.90)$ & 7 & 8 & USA & $\begin{array}{l}\text { Brown } \\
\text { University }\end{array}$ \\
\hline Beltran,Himisha & 34 & $5(39.70)$ & 41 & 5 & USA & $\begin{array}{l}\text { Harvard } \\
\text { Medical School }\end{array}$ \\
\hline Sboner,Andrea & 32 & $6(37.40)$ & 45 & 3 & USA & $\begin{array}{l}\text { Cornell } \\
\text { University }\end{array}$ \\
\hline $\begin{array}{l}\text { Elemento, } \\
\text { Olivier }\end{array}$ & 31 & $7(36.20)$ & 58 & 2 & USA & $\begin{array}{l}\text { Cornell } \\
\text { University }\end{array}$ \\
\hline Kurzrock,R. & 30 & $8(35.00)$ & 84 & 1 & USA & $\begin{array}{l}\text { University of } \\
\text { California San } \\
\text { Diego }\end{array}$ \\
\hline Liu,Ying & 29 & $9(33.90)$ & 14 & 7 & China & $\begin{array}{l}\text { iCarbonX Co } \\
\text { Ltd }\end{array}$ \\
\hline $\begin{array}{l}\text { Mosquera,Juan } \\
\text { Miguel }\end{array}$ & 28 & $10(32.70)$ & 44 & 4 & USA & $\begin{array}{l}\text { Cornell } \\
\text { University }\end{array}$ \\
\hline
\end{tabular}

Total Publications (TP) is the number of papers produced in the current data set, which can also be understood as the output frequency of a researcher in its research field. The h-index is another measurement method, it represents the number $h$ of the papers having a least $h$ citations among a country/territory's number of publications, which is simple and handy [29]. The h-index and TP deputize for the scholarly influence and quality of publications of a country which has many advantages compared with other bibliometric methods. We tried to estimate the academic level of researchers related 
to precision medicine on a global level by employing these indexes. Li, Jing (Southern Medical University China) published the most research on precision medicine with 86 papers, but ranked six based on $\mathrm{h}$ index. Followed by Zhang Ya (Xian Jiaotong University - China) with 38 papers and Lee, Jinhyuk (Korea Research Institute of Bioscience \& Biotechnology (KRIBB) - Korea) with 35 papers, whose h-index ranks No.7, No.9 respectively. This is somewhat surprising since the analysis notes the author's rank in the number of papers does not exactly match the $h$-index, We are aware that there may not exists a most reliable independent parameter to evaluate the quality of research, which presents some cues for a further approach that the way to earn an accurate and complete results not be supposed to be based on isolated indicators but rather on the integration of various indicators, which is why these indicators are chosen as the basis for analysis by us.

\section{G. Research hotpots.}

Bibliometric mapping is a complex network analytical technique, it attempts to extract data from paper sets and then create networks based on co-occurrences, likenesses, or other links to that data, which can build and visualise the structure inherent to a set of publications [30]. Co-occurrence analysis and visualised research can be used to show the aroused general interest and be an important indicator to track scientific development [30]. In this study, paper records were loaded into the Science of Science (Sci2) Tool to create and visualise a word co-occurrence network to identify the research topics of precision medicine papers [31]. The network was pruned by dropping isolate nodes and edges to increase the clarity of the map. The final network consists of 100 nodes and 100 edges. Figure 5 presents the frequency degree of 23,287 keywords appearing in our search results. Nodes are sized relative to the citation count of papers, and colored laid in the communities identified by the community detection algorithm, the smaller the node and the lighter color represent the smaller weight. The thickness of lines is an indication which was determined by the occurrence frequency of keywords at the same time in these papers to show the correlation between keywords [32]. At the same time, VOSviewer analyzed the keywords and applied different colors to keywords based on average time they are published (Fig. 6).

As drawn in Fig. 5 and Fig. 6, the 23,287 identified keywords could be classified into five clusters: "oncology study", "biochemistry molecular biology study", "genetics heredity study", "medicine research experimental study" and "pharmacology pharmacy study". The strength of these relationships was divided into specific thematic groups and represented how interrelated and frequent its co-occurrence was with other terms based on their clustering with a certain constellation of terms. In the "oncology study" cluster, the most frequent values were breast-cancer, cell lung-cancer, targeted therapy, colorectalcancer and lung-cancer. In the cluster of" biochemistry molecular biology study", the most commonly occurs were biomarkers, mutations, expression and biomarker. In the "genetic heredity study" cluster, the main keywords were genomics, gene-expression, genetics, genome-wide association and pharmacogenomics. In the "medicine research experimental study" cluster, the frequently used keywords were double-blind, open-label, heterogeneity and variants. In the cluster of "pharmacology pharmacy study", the main keywords were pharmacogenetics and acquired-resistance. These results indicate the accumulating effects of research related to precision medicine. The increasing burden due to cancer has 
attracted scientific concern, with the highest total keywords number of cancers in precision medicine. Several recent examples have dramatically underlined that precision medicine received the deepest concern due to its characteristics of the relative research and being broadly applied in this field. It noted that targeted therapy based on the increasing technique of biochemistry molecular biology that restoring the health of patients suffering from cancer is best accomplished by the notion of precision medicine. But in the field of pharmacogenomic, there is an even larger uncertainty that pharmacogenomic tests have no direct influence on patient outcomes, but rather improve a clinician's decisions about the treatment which remains to be studied in more detail [7]. It is the word "ethics" that arrests us which is here to be viewed in the result, accordingly, we consider the possibility there may be a lack of attention towards precision medicine ethics in medicine and health. With these results, investigators could get very current information along with gain the message ditch make varied development and be encouraged to conduct further research. It can help funding agencies develop more reasonable investment plans and provide a basis for health care policy formulation.

\section{H. Bibliographic coupling analysis.}

Bibliographic coupling was first reported in 1963 by American scholar M·M·Kessler. In this study, a cocitation relationship is considered exiting when two papers appear in the same paper as the reference, and it can be measured by citation coupling. We introduce the reference co-citation network, which came into being the communion of references among papers to provide farsightedness on how references were used and establish connections [33]. Figure 7 presents the bibliographic coupling network of top 30 cocitations of publications from 2010 to 2019 , which were pertaining to precision medicine.

After analysis, the highest strength of citation coupling are the paper "Cellular and molecular immunological mechanisms in patients with atopic dermatitis" written by Werfel Thomas and Allam Jean-Pierre, and "EAACI Molecular Allergology User's Guide" written by P. M. Matricardi and J. KleineTebbe. They both published in 2016. The first paper shows IgE-mediated reactions and allergic diseases are discussed from a novel molecular perspective [34], and the second discuss that the targeted molecules can be expressed on or drive the cellular players infiltrating the skin, which is an effective treatment on pruritus of Atopic dermatitis (AD) [32]. After analysis, a set of papers of the second weight are the paper "Fluorescent chemical probes for accurate tumor diagnosis and targeting therapy." written by Gao Min and Yu Fabiao in 2017, and "Intraoperative imaging-guided cancer surgery: from current fluorescence molecular imaging methods to future multi-modality imaging technology." written by Chi Chongwei and Du Yang in 2014. The first paper shows the fluorescence imaging bases on precision medicine is a vital and rapidly developing field for interventional surgical imaging, as well as tumor diagnosis and therapy. The second paper focused on multi-modality imaging technology basing on precision medicine for intraoperative imaging-guided cancer surgery [11]. And other papers reported that there is still a lack of real data on clinical utility which is not model-based or derived from selective trials to support precision medicine technologies [34]. In conclusion to this, it becomes obvious that targeted therapy based on biochemistry molecular biology is restoring the health of patients suffering from cancer, which can represent a promising alternative for the treatment in future. It can also be seen that the lines 
in this figure have been intensive gradually since 2010, which reflects that there are major breakthroughs in the research field, and the research field is relatively concentrated. The papers with extraordinary strength of citation coupling have been of great significance for future research. The certain continuity in research of scholars can be found through the weight of citation couping which is influenced by the development of new theories and methods [35]. They would continue to pay attention to the problem and solve it from different perspectives. And they usually keep identical for the citation of references among the authors in the same team.

I. Most frequently cited papers and citation visualization analysis.

Citation analysis is formal, scholarly founded, and the indicators based on it are valuable and reveal measures of the impact of the research, which can additionally be supplemented in the evaluation of the research topic. We used HistCite to generate the most cited papers involved in precision medicine, and get the visual citation chronicle which can be used to help to identify the classic paper in the field quickly. Entering 8,566 papers into HistCite and the top 30 LCS papers been elected into and made citation chronological chart (Fig. 8). The size of the dot represents the cited number of papers, the arrows point to the papers which are cited [36]. The total amount of times these publications have been cited is 1,602, with each paper been cited 53.4 times in other publications on average. Citation chronological chart reflects the annual change trend, evolution and inheritance relation of research papers in precision medicine. Paper No.1165: ("A New Initiative on Precision Medicine" (which was published in 2015)) received the highest number of citations, which is the important papers in the development of precision medicine in recent years, and indicate that this paper has been recognized by many peers. From the proposed analysis, it may lead to a more rapid and more active developing of research work in precision medicine of 2015 , as we can see, there were several highly cited papers during this period. Such as No.339 ("Precision Medicine - Personalized, Problematic, and Promising”) was written by McGranahan, N; Swanton, C, which was published in the New England Journal of Medicine. No.418 ("The Precision Medicine Initiative A New National Effort") written by Pollock, Collins, FS; Varmus, $\mathrm{H}$ has been cited 62 times in general during the past ten years.

HistCite also can calculate the local citation score (LCS). In this study, the minimum LCS is 34 , and the maximum LCS is 555 . Table 5 lists the top 10 high LCS papers in this field which are likewise the most influential. These are the principal references in the development of precision medicine in recent years. It was found that the top ten high-impact papers were mainly published in seven different journals: New England Journal of Medicine, Jama-Jam Med Association, Cell. These journals are worth studying carefully which may have promising beneficial effects in later research on precision medicine, they may be of significance from the aspect of being used as references. 
Table 5

Top 10 LCS articles in publications of precision medicine during 2010-2019

\begin{tabular}{|c|c|c|c|c|c|}
\hline $\begin{array}{l}\text { ID } \\
\text { Histcite }\end{array}$ & Author,refs. & Title & Journal & Year & LCS \\
\hline 1165 & $\begin{array}{l}\text { Chambers, DA } \\
\text { et al, (3) }\end{array}$ & A New Initiative on Precision Medicine & $\begin{array}{l}\text { New England } \\
\text { Journal of } \\
\text { Medicine }\end{array}$ & 2015 & 555 \\
\hline 399 & $\begin{array}{l}\text { McGranahan, } \\
\mathrm{N} \text { et al, }(1)\end{array}$ & $\begin{array}{l}\text { Precision Medicine - Personalized, } \\
\text { Problematic, and Promising }\end{array}$ & $\begin{array}{l}\text { New England } \\
\text { Journal of } \\
\text { Medicine }\end{array}$ & 2015 & 144 \\
\hline 600 & $\begin{array}{l}\text { Bayer, R et al, } \\
\text { (38) }\end{array}$ & Preparing for Precision Medicine & $\begin{array}{l}\text { New England } \\
\text { Journal of } \\
\text { Medicine }\end{array}$ & 2012 & 87 \\
\hline 418 & $\begin{array}{l}\text { Collins, FS et } \\
\text { al, (2) }\end{array}$ & $\begin{array}{l}\text { The Precision Medicine Initiative A } \\
\text { New National Effort }\end{array}$ & $\begin{array}{l}\text { Jama-Journal } \\
\text { of the } \\
\text { American } \\
\text { Medical } \\
\text { Association }\end{array}$ & 2015 & 62 \\
\hline 907 & $\begin{array}{l}\text { Khoury, MJ et } \\
\text { al, (9) }\end{array}$ & $\begin{array}{l}\text { Integrative Clinical Genomics of } \\
\text { Advanced Prostate Cancer }\end{array}$ & Cell & 2015 & 52 \\
\hline 853 & $\begin{array}{l}\text { Gaziano, JM et } \\
\text { al, (37) }\end{array}$ & $\begin{array}{l}\text { Preemptive Clinical } \\
\text { Pharmacogenetics Implementation: } \\
\text { Current Programs in Five US Medical } \\
\text { Centers }\end{array}$ & $\begin{array}{l}\text { Annual } \\
\text { Review of } \\
\text { Pharmacology } \\
\text { and } \\
\text { Toxicology, Vol } \\
55\end{array}$ & 2015 & 49 \\
\hline 1657 & $\begin{array}{l}\text { LaFleur, R et al, } \\
\text { (39) }\end{array}$ & $\begin{array}{l}\text { Treatable traits: toward precision } \\
\text { medicine of chronic airway diseases }\end{array}$ & $\begin{array}{l}\text { European } \\
\text { Respiratory } \\
\text { Journal }\end{array}$ & 2016 & 47 \\
\hline 276 & $\begin{array}{l}\text { Ciardiello, F et } \\
\text { al, (40) }\end{array}$ & $\begin{array}{l}\text { Precision medicine in patients with } \\
\text { allergic diseases: Airway diseases } \\
\text { and atopic dermatitis-PRACTALL } \\
\text { document of the European Academy } \\
\text { of Allergy and Clinical Immunology } \\
\text { and the American Academy of Allergy, } \\
\text { Asthma \& Immunology }\end{array}$ & $\begin{array}{l}\text { Journal of } \\
\text { Allergy and } \\
\text { Clinical } \\
\text { Immunology }\end{array}$ & 2016 & 39 \\
\hline 1165 & $\begin{array}{l}\text { Chambers, DA } \\
\text { et al, (41) }\end{array}$ & $\begin{array}{l}\text { Limits to Personalized Cancer } \\
\text { Medicine }\end{array}$ & $\begin{array}{l}\text { New England } \\
\text { Journal of } \\
\text { Medicine }\end{array}$ & 2016 & 38 \\
\hline 399 & $\begin{array}{l}\text { McGranahan, } \\
\mathrm{N} \text { et al, (42) }\end{array}$ & $\begin{array}{l}\text { Integrative Clinical Sequencing in the } \\
\text { Management of Refractory or } \\
\text { Relapsed Cancer in Youth }\end{array}$ & $\begin{array}{l}\text { Jama-Journal } \\
\text { of the } \\
\text { American } \\
\text { Medical } \\
\text { Association }\end{array}$ & 2015 & 34 \\
\hline
\end{tabular}

\section{Conclusion And Limitations}


Precision medicine plays an important role in the field of medicine year by year. In this paper, we focused on the global development of precision medicine during the past ten years by bibliometric. The results shown above can be summarised as follows. The research on precision medicine developed relatively slowly from 2010 to 2013, but since 2014 the number of papers has growing rapidly. It is shown that precision medicine has attracted great attention from scholars all over the world in recent years. USA leads the research of this field. Harvard University is the main research institution, which also comes from the United States and represents the highest academic standards in the world. And research institutions from China mainland, Japan, Singapore, and other East Asian countries/regions hold more important places and emerged as developing players in the field. To a certain extent, there is a significant positive correlation between the progress of scientific research and high economic level, the growth of economic strength in Asia and the development. Scholars can hence interest in improving opportunities by collaboration and assist in shaping research strategies globally. Applications of the notion of precision medicine play an important role in the use of diagnosis and clinical treatment, but there are still many questions to be properly explored and evaluated. Such as the lack of real data on the clinical utility to support precision medicine technologies and larger uncertainty that pharmacogenomic tests have no direct influence on patient outcomes. Among them, the key one that restrains further development of this field is how to raise the actual clinical outcomes effectively. It is predicted that adequate precise clinical practice data from well-conducted trials and studies will be carried out in the next years. Precision medicine is expected to continue to greatly expand in the next ten years and begin to be widely used as soon as these questions are solved. The direction for future research is the involvement of social participation and global cooperation in precision medicine research for gaining better results through the balance of technology and public health.

And yet, several limitations to the study should also be considered. First, we only got papers from SCIE and PubMed, which mainly include the studies in English, and the search words are limited to the "personalized" or "precision" narrowly, These may reduce the breadth and depth of the results, papers in other languages and published in recent are easy to be ignored. After searching we found some papers did not have a complete affiliation. Thus these were not portioned out to the fixed countries, these countries may have been underestimated.

\section{Declarations}

\section{Ethics approval and consent to participate}

Not applicable.

\section{Consent for publication}

Not applicable.

\section{Availability of data and materials}


The datasets used and analyzed during the current study are available from the corresponding author upon reasonable requests.

\section{Competing interests}

The authors declare that there is no conflict of interest associated with this work.

\section{Funding}

This work was supported by "the Fundamental Research Funds for the Central Universities" (Grant No. 2020-JYB-ZDGG-067).

\section{Authors' contributions}

Baoyue Zhang and Youliang Huang designed the experiments and drafted the manuscript. Bo Ao, Sajid Ali, Tianhui Xuan, Xinyue Lu, Junbai Chen, Pengfei Bao, and Shuang Yang mainly performed the experiments and analyzed the data. Qian Huang, Ruifeng Li, and Zhongwei Hou reviewed the manuscript. All authors read and approved the final manuscript.

\section{Acknowledgements}

The authors are very grateful to the referees and anonymous reviewers for their helpful comments and suggestions. The authors also thank the authors of the original studies included in this analysis.

\section{References}

1. Jameson JL, Longo DL: Precision Medicine - Personalized, Problematic, and Promising. New England Journal of Medicine 2015, 372(23):2229-2234.

2. Ashley EA: The precision medicine initiative: a new national effort. JAMA 2015, 313(21):2119-2120.

3. Collins FS, Varmus H: A new initiative on precision medicine. N Engl J Med 2015, 372(9):793-795.

4. Xiong HY, Alipanahi B, Lee LJ, Bretschneider H, Merico D, Yuen RKC, Hua YM, Gueroussov S, Najafabadi HS, Hughes TR et al: The human splicing code reveals new insights into the genetic determinants of disease. Science 2015, 347(6218).

5. Desmond-Hellmann S: Toward precision medicine: a new social contract? Sci Trans/ Med 2012, 4(129):129ed123.

6. Graur D, Zheng Y, Price N, Azevedo RB, Zufall RA, Elhaik E: On the immortality of television sets: "function" in the human genome according to the evolution-free gospel of ENCODE. Genome Biol Evol 2013, 5(3):578-590.

7. Jones PA, Issa JPJ, Baylin S: Targeting the cancer epigenome for therapy. Nature Reviews Genetics 2016, 17(10):630-641.

8. Robinson D, Van Allen EM, Wu YM, Schultz N, Lonigro RJ, Mosquera JM, Montgomery B, Taplin ME, Pritchard CC, Attard G et al: Integrative Clinical Genomics of Advanced Prostate Cancer. Cell 2015, 
161(5):1215-1228.

9. Bilkey GA, Burns BL, Coles EP, Mahede T, Baynam G, Nowak KJ: Optimizing Precision Medicine for Public Health. Front Public Health 2019, 7:42.

10. Insel TR: The NIMH Research Domain Criteria (RDoC) Project: Precision Medicine for Psychiatry. American Journal of Psychiatry 2014, 171(4):395-397.

11. Min G, Fabiao Y, Changjun L, Jaebum C, Lingxin C: Fluorescent chemical probes for accurate tumor diagnosis and targeting therapy. Chemical Society reviews 2017, 46(8).

12. Blum M: Digital health center at UCSF clears the path for innovation. The new initiative aims to drive precision medicine forward. Interview by Rajiv Leventhal. Healthc Inform 2013, 30(6):44-46.

13. Perianes-Rodriguez A, Waltman L, van Eck NJ: Constructing bibliometric networks: A comparison between full and fractional counting. $J$ Informetr 2016, 10(4):1178-1195.

14. Min HS, Yun EH, Park J, Kim YA: Cancer News Coverage in Korean Newspapers: An Analytic Study in Terms of Cancer Awareness. J Prev Med Public Health 2020, 53(2):126-134.

15. Tatry MV, Fournier D, Jeannequin B, Dosba F: EU27 and USA leadership in fruit and vegetable research: a bibliometric study from 2000 to 2009. Scientometrics 2014, 98(3):2207-2222.

16. Zeinoun P, AkI EA, Maalouf FT, Meho LI: The Arab Region's Contribution to Global Mental Health Research (2009-2018): A Bibliometric Analysis. Front Psychiatry 2020, 11:182.

17. Deng Z, Wang H, Chen Z, Wang T: Bibliometric Analysis of Dendritic Epidermal T Cell (DETC) Research From 1983 to 2019. Front Immunol 2020, 11:259.

18. Weng LM, Zheng YL, Peng MS, Chang TT, Wu B, Wang XQ: A Bibliometric Analysis of Nonspecific Low Back Pain Research. Pain Res Manag 2020, 2020:5396734.

19. Yu Q, Tan S, Ren Y, He M, Fu X, Peng Y, Tang X: Bibliometric analysis of the $\mathbf{1 0 0}$ most-cited articles in the field of hepatology. Gastroenterol Hepatol 2020.

20. Carpenter CR, Cone DC, Sarli CC: Using Publication Metrics to Highlight Academic Productivity and Research Impact. Acad Emerg Med 2014, 21(10):1160-1172.

21. Zhou X, Zhao G: Global liposome research in the period of 1995-2014: a bibliometric analysis. Scientometrics 2015, 105(1):231-248.

22. Garg KC, Kumar S, Madhavi Y, Bahl M: Bibliometrics of global malaria vaccine research. Health Info Libr J 2009, 26(1):22-31.

23. Bernabò N, Greco L, Mattioli M, Barboni B: A scientometric analysis of reproductive medicine. Scientometrics 2016, 109(1):103-120.

24. Huang $Y$, Huang $Q$, Ali $S$, Zhai X, Bi X, Liu R: Rehabilitation using virtual reality technology: a bibliometric analysis, 1996-2015. Scientometrics 2016, 109(3):1547-1559.

25. Chen $\mathrm{CM}$ : CiteSpace II: Detecting and visualizing emerging trends and transient patterns in scientific literature. J Am Soc Inf Sci Technol 2006, 57(3):359-377.

26. Meho LI, Yang K: Impact of data sources on citation counts and rankings of LIS faculty: Web of science versus scopus and google scholar. J Am Soc Inf Sci Technol 2007, 58(13):2105-2125. 
27. Tran BX, Vu GT, Ha GH, Vuong QH, Ho MT, Vuong TT, La VP, Ho MT, Nghiem KP, Nguyen HLT et al: Global Evolution of Research in Artificial Intelligence in Health and Medicine: A Bibliometric Study. $J$ Clin Med 2019, 8(3).

28. Chen H, Jiang W, Yang Y, Yang Y, Man X: Global trends of municipal solid waste research from 1997 to 2014 using bibliometric analysis. J Air Waste Manag Assoc 2015, 65(10):1161-1170.

29. Hirsch JE: Does the $h$ index have predictive power? Proc Natl Acad Sci U S A 2007, 104(49):1919319198.

30. Michalopoulos A, Falagas ME: A bibliometric analysis of global research production in respiratory medicine. Chest 2005, 128(6):3993-3998.

31. Belter CW: A bibliometric analysis of NOAA's Office of Ocean Exploration and Research. Scientometrics 2013, 95(2):629-644.

32. Matricardi PM, Kleine-Tebbe J, Hoffmann HJ, Valenta R, Hilger C, Hofmaier S, Aalberse RC, Agache I, Asero R, Ballmer-Weber B et al: EAACI Molecular Allergology User's Guide. Pediatric Allergy and Immunology 2016, 27.

33. Thomas W, Jean-Pierre A, Tilo B, Kilian E, Stefanie G, Emma G-Y, Wolfram H, Edward K, Hans-Uwe S, Andreas $\mathrm{W}$ et al: Cellular and molecular immunologic mechanisms in patients with atopic dermatitis. The Journal of allergy and clinical immunology 2016, 138(2).

34. Chongwei C, Yang D, Jinzuo Y, Deqiang K, Jingdan Q, Jiandong W, Jie T, Xiaoyuan C: Intraoperative imaging-guided cancer surgery: from current fluorescence molecular imaging methods to future multi-modality imaging technology. Theranostics 2014, 4(11).

35. Cui F, Li J, Ding A, Zhao C, Wang L, Wang X, Li S, Bao Y, Li X, Feng D et al: Conditional QTL mapping for plant height with respect to the length of the spike and internode in two mapping populations of wheat. Theor Appl Genet 2011, 122(8):1517-1536.

36. Valencia GE, Roldan J, Duarte JL: Bibliometric and visualization analysis of sliding mode control research. Contemporary engineering sciences 2018, 11(74):3673-3680.

37. Dunnenberger HM, Crews KR, Hoffman JM, Caudle KE, Broeckel U, Howard SC, Hunkler RJ, Klein TE, Evans WE, Relling MV: Preemptive Clinical Pharmacogenetics Implementation: Current Programs in Five US Medical Centers. In: Annual Review of Pharmacology and Toxicology, Vol 55. Edited by Insel PA, vol. 55. Palo Alto: Annual Reviews; 2015: 89-+.

38. Mirnezami R, Nicholson J, Darzi A: Preparing for Precision Medicine. N Eng/ J Med 2012, 366(6):489491.

39. Agusti A, Bel E, Thomas M, Vogelmeier C, Brusselle G, Holgate S, Humbert M, Jones P, Gibson PG, Vestbo $\mathrm{J}$ et al: Treatable traits: toward precision medicine of chronic airway diseases. Eur Resp $\mathrm{J}$ 2016, 47(2):410-419.

40. Muraro A, Lemanske RF, Hellings PW, Akdis CA, Bieber T, Casale TB, Jutel M, Ong PY, Poulsen LK, Schmid-Grendelmeier $P$ et al: Precision medicine in patients with allergic diseases: Airway diseases and atopic dermatitis-PRACTALL document of the European Academy of Allergy and Clinical 
Immunology and the American Academy of Allergy, Asthma \& Immunology. J Allergy Clin Immunol 2016, 137(5):1347-1358.

41. Tannock IF, Hickman JA: Limits to Personalized Cancer Medicine. N Engl J Med 2016, 375(13):12891294.

42. Mody RJ, Wu YM, Lonigro RJ, Cao XH, Roychowdhury S, Vats P, Frank KM, Prensner JR, Asangani I, Palanisamy $\mathrm{N}$ et al: Integrative Clinical Sequencing in the Management of Refractory or Relapsed Cancer in Youth. JAMA-J Am Med Assoc 2015, 314(9):913-925.

\section{Figures}

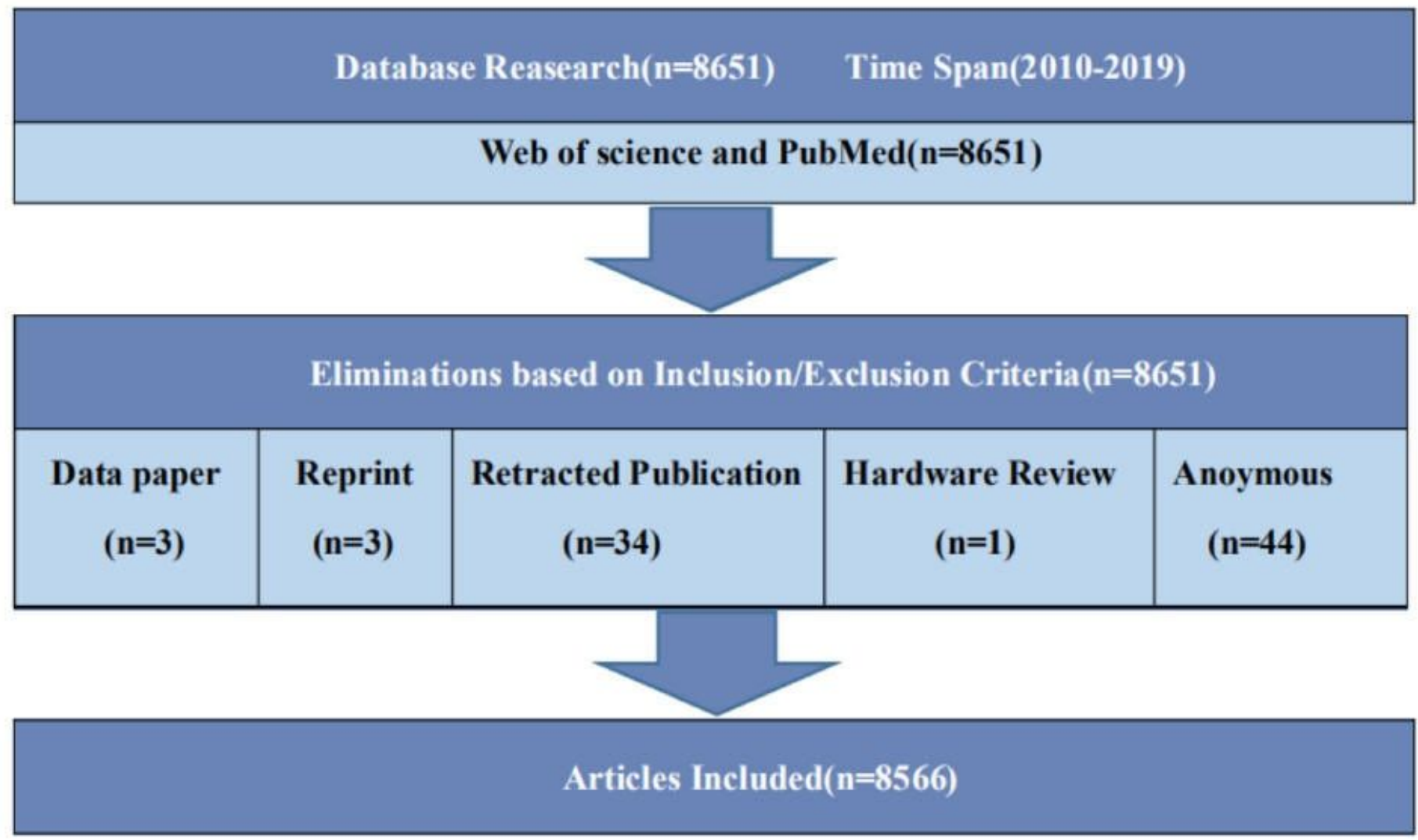

Figure 1

Search strategy used for the study. This figure shows the inclusion and exclusion criteria. 


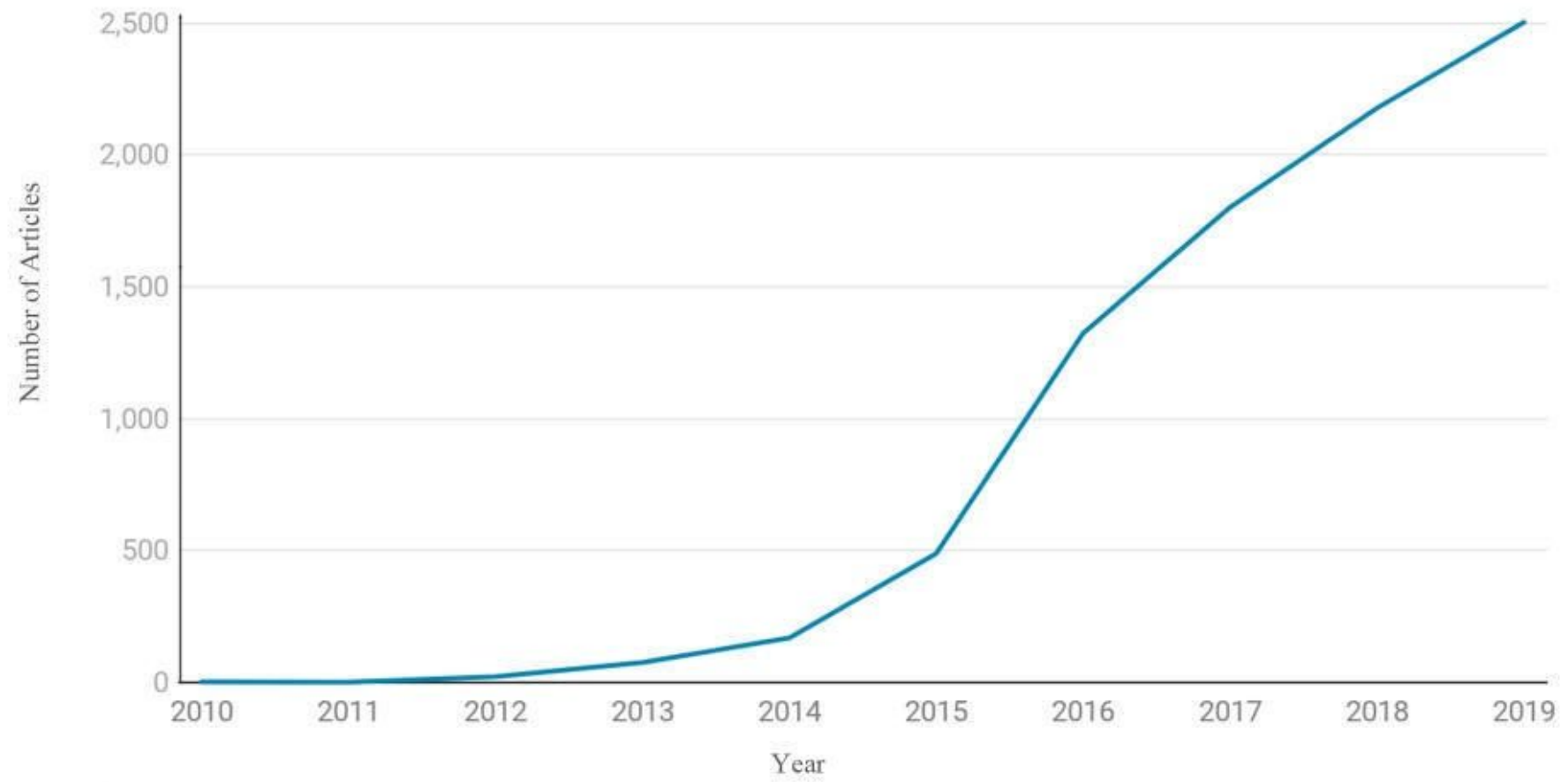

Figure 2

Worldwide growth for publications in precision medicine research (2010-2019). This figure reveals the development tendency of this field from a macroeconomic perspective. 


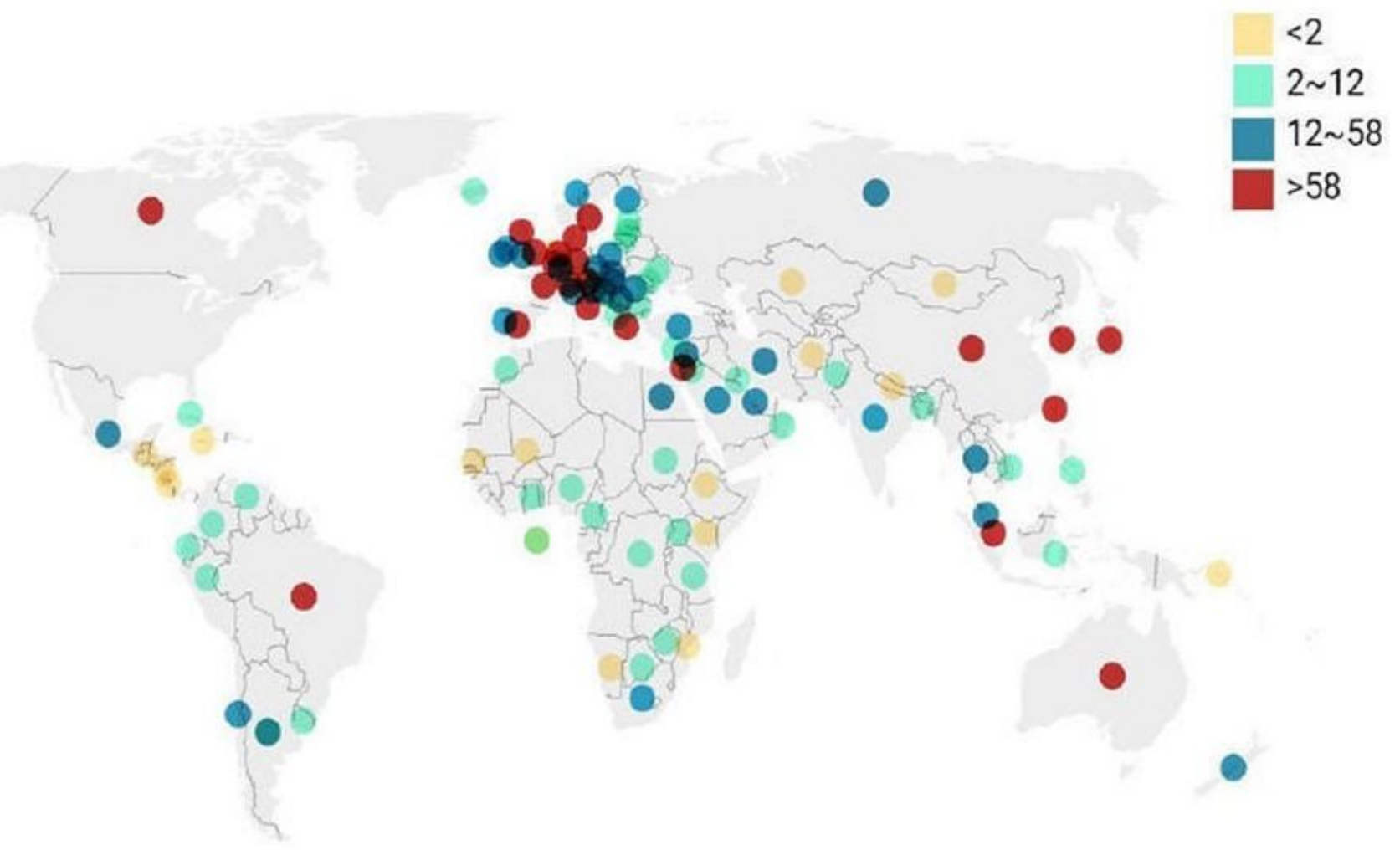

Figure 3

Worldwide distribution for nations in precision medicine research (2010-2019). This figure illustrates the global distribution of published publications. Note: The designations employed and the presentation of the material on this map do not imply the expression of any opinion whatsoever on the part of Research Square concerning the legal status of any country, territory, city or area or of its authorities, or concerning the delimitation of its frontiers or boundaries. This map has been provided by the authors. 


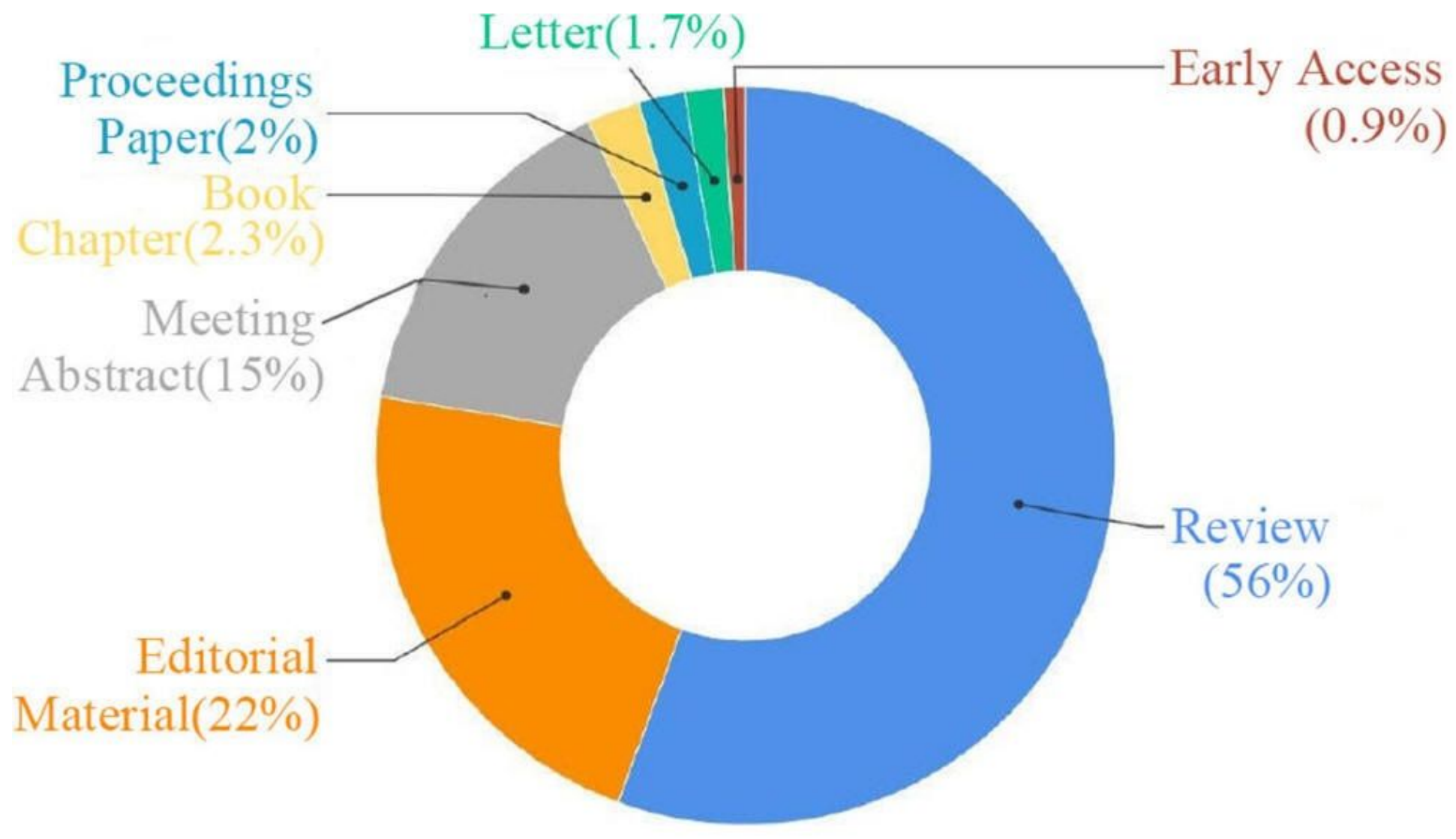

Figure 4

Published papers on precision medicine based on document type. This figure shows the different ratios of document types.

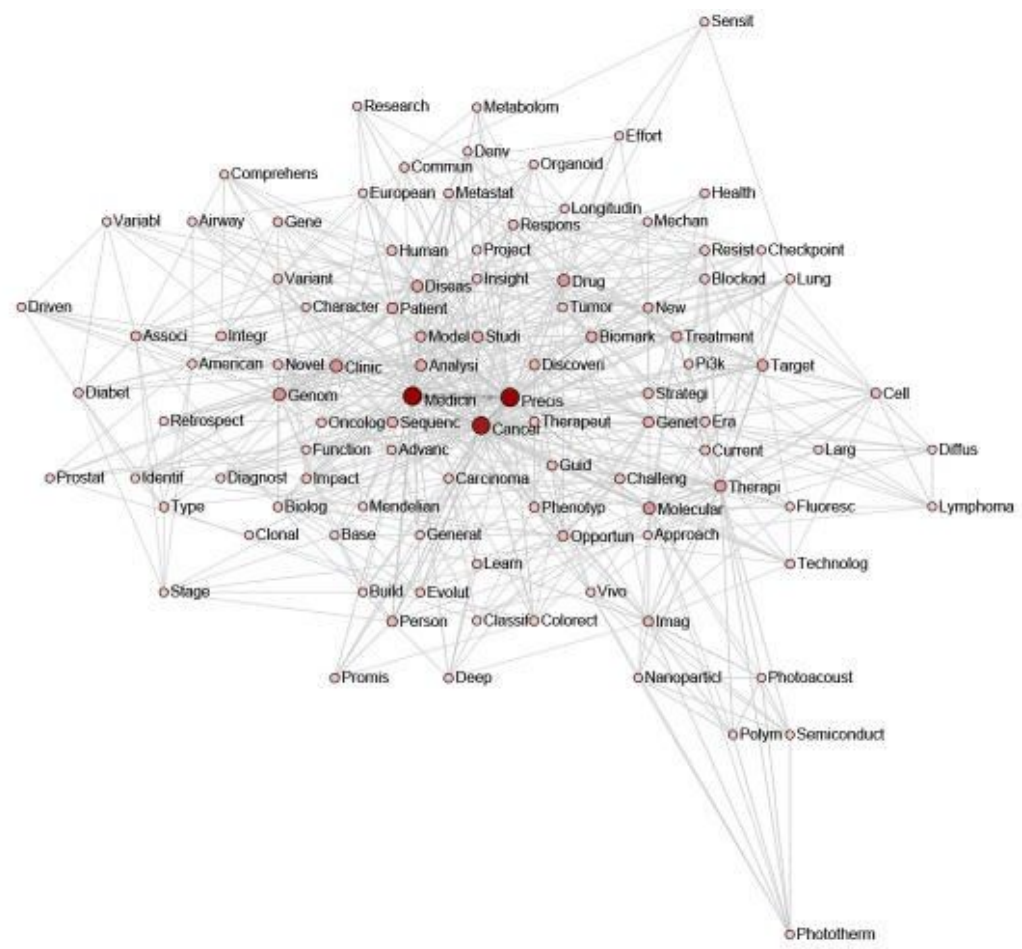

Figure 5 
Keywords co-occurrence network map by Sci2. The figure presents the prevalence of keywords appearing in our search results.

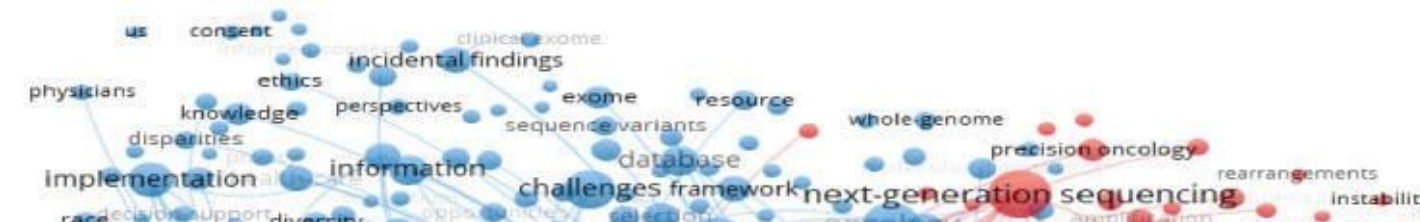

race $=0$ chailenges frameworknext-genecation seguencing ingtability

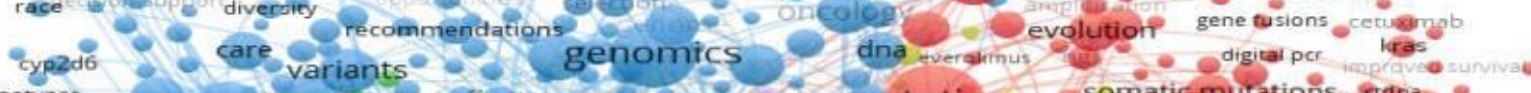
cyp2c19 genotypes pharmacogenomics cest-efrectergess

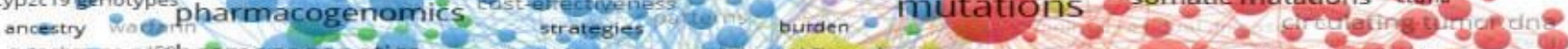

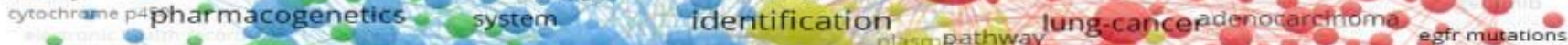

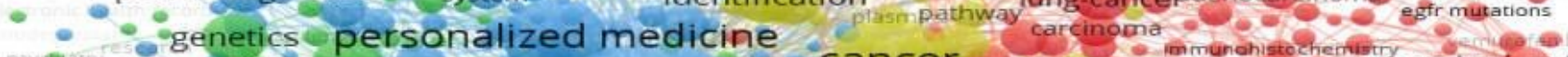

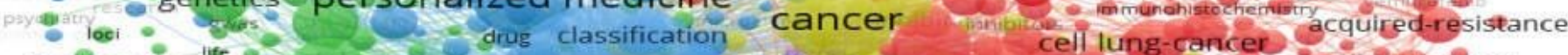
blood-pressure lifs -

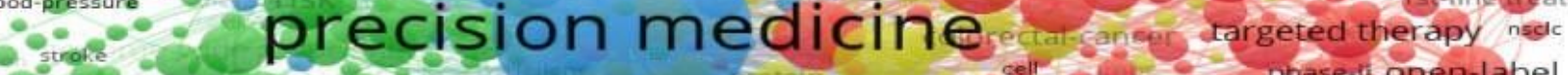

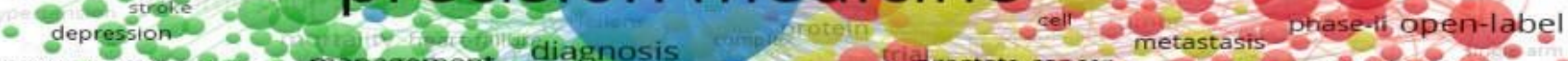

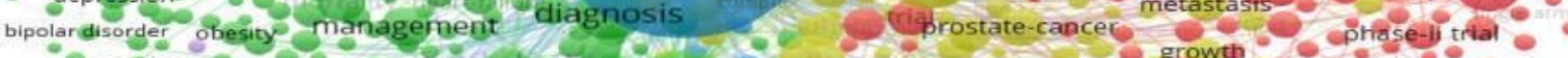

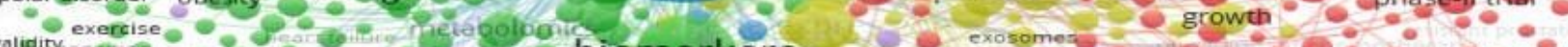

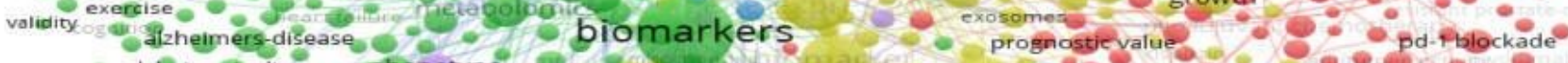

alzheimer's disease pbenotype treatment clinical-trialifferentation cells 0

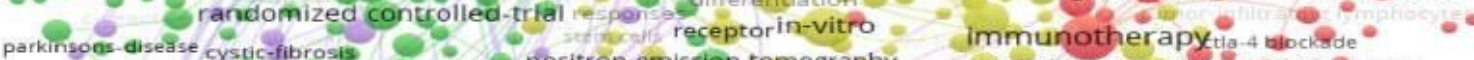
5nositron-emission-tomography epithelai-mesenchymaleransie

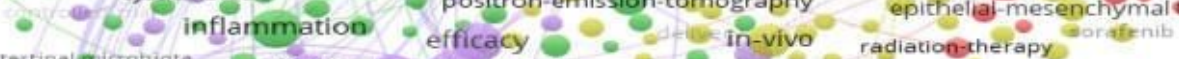
cepditestinalqicrobioto sepsis double-blind regulatory-cells tgrbeta Iung-renciphenotypes, septicshock rheumatoid arthritis asthma septicshock theranostics rity delivery

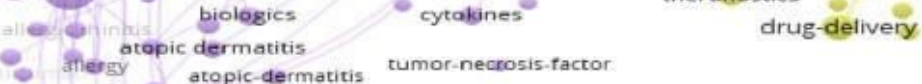
severeasthrna ige innate lymphoid-cells

\section{Figure 6}

Keywords co-occurrence network of precision medicine related publications by VOSviewer. This figure identified five research clusters of keywords. 
Matricardi Pm, 2016, Pediat Allerg Imm-uk, V27, P1, Doi 10 1111/pai 12563

OWerfel T, 2016, J Allergy Clin Immun, V138, P336, Doi 10.1016/.jaci.2016.06.010

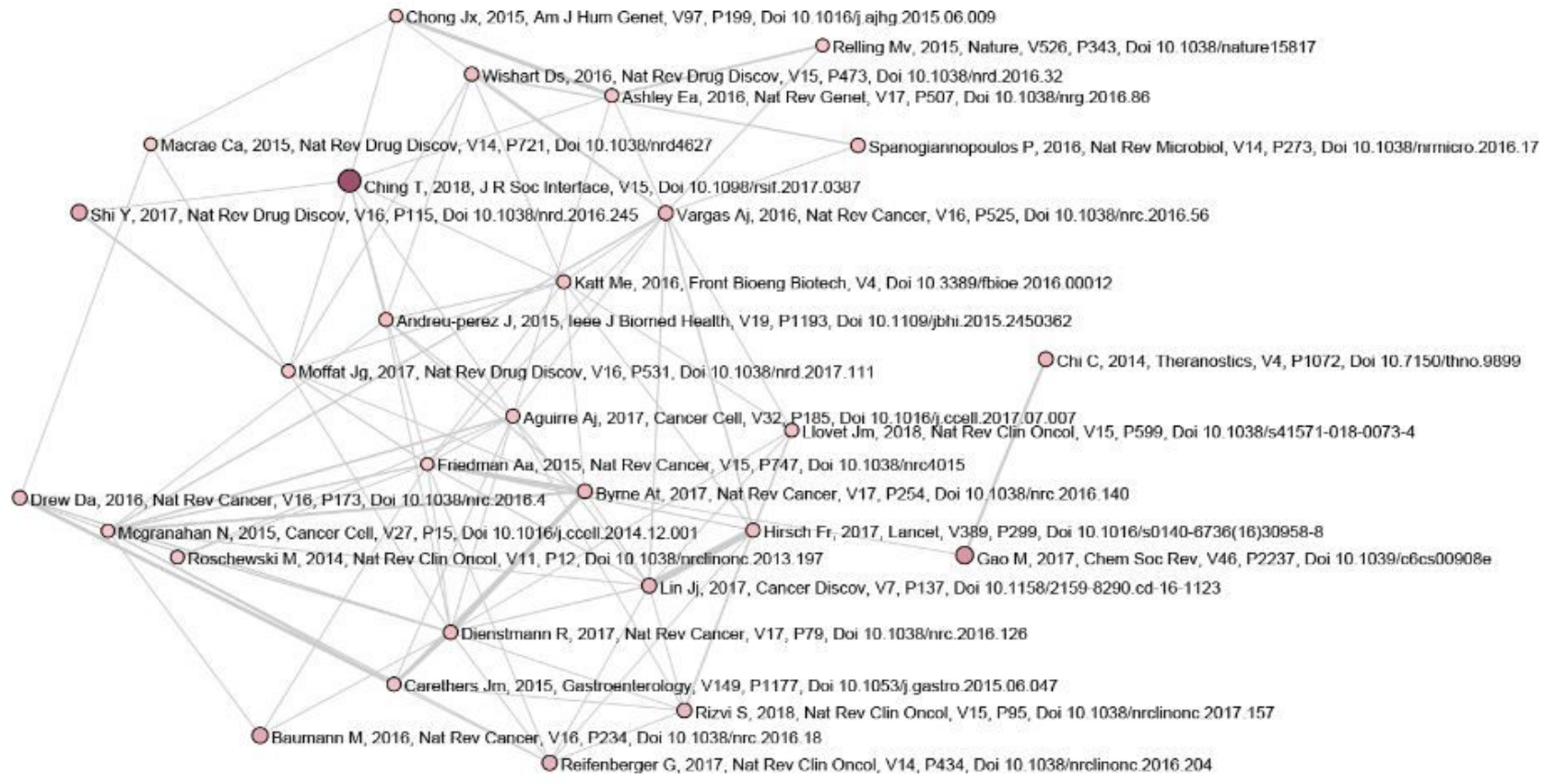

Figure 7

Couping co-citation network of publications by Sci2. This figure presents the top 30 co-citation network of publications from 2010 to 2019, which were related to precision medicine. 


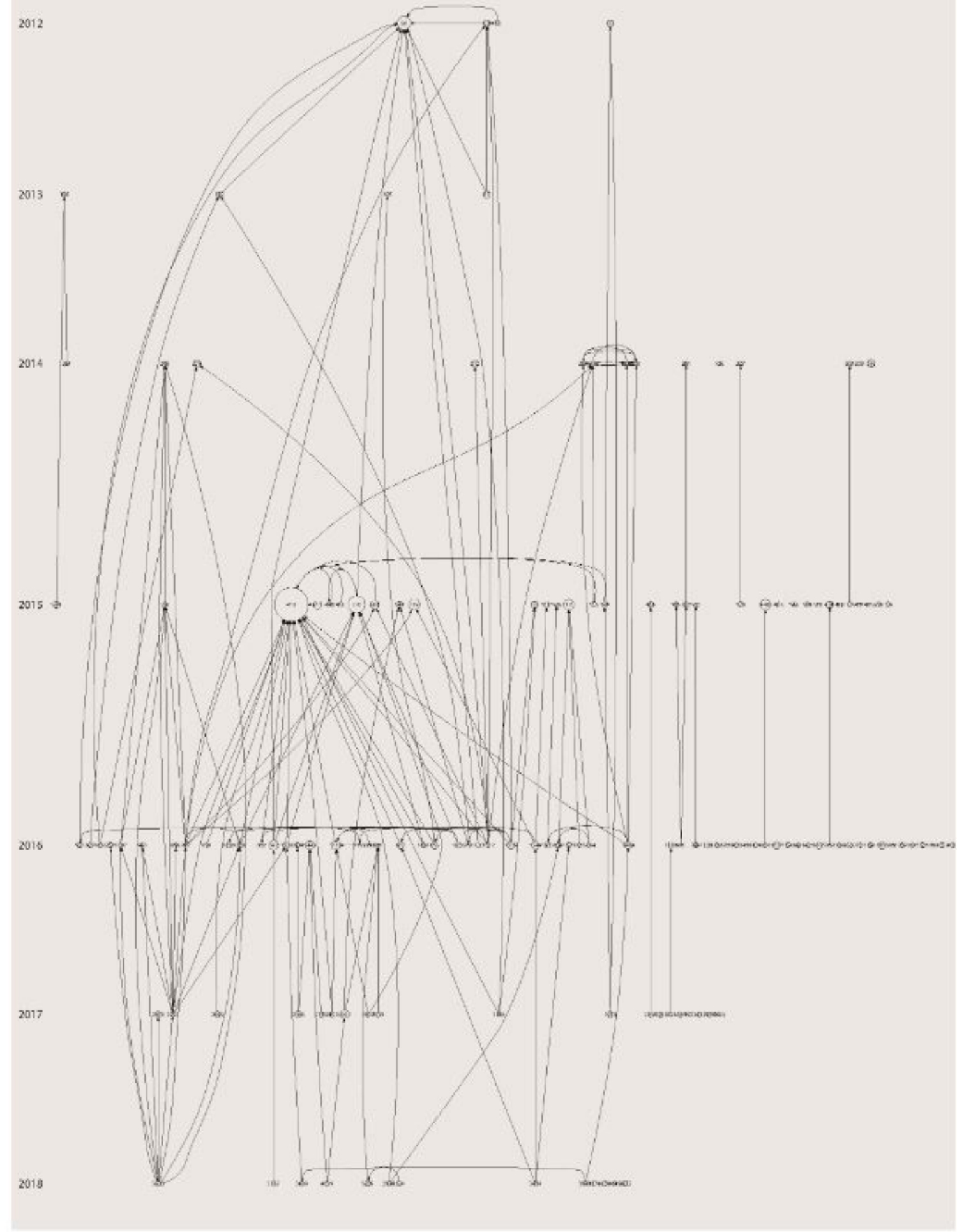

\section{Figure 8}

Literatures chronological chart by HistCite. The figure points the top 30 papers with local citation score. 